\title{
Incidentally gathered natural history information on Bullsnakes (Pituophis catenifer sayi) in southeastern Alberta
}

\author{
G. Lawrence Powell ${ }^{1, *}$, Peter Peller ${ }^{2}$, and Anthony P. Russell ${ }^{1}$
}

${ }^{1}$ Department of Biological Sciences, University of Calgary, 2500 University Drive NW, Calgary, Alberta T2N 1N4 Canada
${ }^{2}$ Spatial and Numeric Data Services, Libraries and Cultural Resources, University of Calgary, 2500 University Drive NW,
Calgary, Alberta T2N 1N4 Canada
*Corresponding author: lpowell@ucalgary.ca

Powell, G.L., P. Peller, and A.P. Russell. 2018. Incidentally gathered natural history information on Bullsnakes (Pituophis catenifer sayi) in southeastern Alberta. Canadian Field-Naturalist 132(2):140-149. https://doi.org/10.22621/cfn.v132i2.2046

\begin{abstract}
We present observations on Bullsnakes (Pituophis catenifer sayi) gathered during a study of Prairie Rattlesnakes (Crotalus viridis) in a multiple-use, mixed grass landscape adjacent to the South Saskatchewan River, $\sim 30 \mathrm{~km}$ northeast of Medicine Hat, Alberta, in May-October 1997. Hibernacula shared with rattlesnakes were located close to the river. We captured 31 Bullsnakes, either in a drift fence array around a hibernaculum or by hand; three were recaptured once. Emergence from the hibernaculum ended in mid-May, and return to it began in early September. A gap in capture events occurred between early July and late August, possibly attributable to fossorial activity during the height of the summer. The sex ratio of captured adult snakes was 0.64 in favour of males. Males attained the greatest maximum body sizes, but there was no significant size dimorphism by sex. Bullsnakes were assignable to juvenile, subadult, and adult classes by body size. Most captures were made on slopes in the immediate vicinity of the river, in areas classed as "thin breaks", but four captures, about $7 \mathrm{~km}$ east of the river, provide evidence of long-distance movements from hibernacula. Captures were seldom made in the vicinity of anthropogenic features. Gas field development has increased greatly in the years since these data were collected. Our findings provide a baseline for Bullsnake population responses to such changes.
\end{abstract}

Key words: Bullsnake; Pituophis catenifer sayi; habitat; size distribution; hibernacula; landscape use; human interactions; Alberta

\section{Introduction}

Gophersnake (Pituophis catenifer) is a large oviparous constrictor occupying a variety of habitats across much of western North America (Ernst and Ernst 2003). Populations are divided geographically among several subspecies (Ernst and Ernst 2003). In Alberta, populations of Bullsnakes (P. c. sayi) are found scattered throughout the dry mixed grass and mixed grass subregions of the Grassland Natural Region, clustering around the vicinities of badlands terrain and major and minor river valleys (Russell and Bauer 2000; Kissner and Nicholson 2003; COSEWIC 2017). Summaries of what is known of Bullsnake ecology in Alberta are provided by Kissner and Nicholson (2003), Wright (2008), and COSEWIC (2017). Fortney et al. (2012), Martino et al. (2012), Gardiner et al. (2013), and Somers et al. (2017) have examined various aspects of Bullsnake habitat use and movement in southeastern Saskatchewan.

Bullsnake is currently considered to be a species of special concern (COSEWIC 2017). There is evidence of recent range contraction in Alberta (Russell and Bauer 2000; Kissner and Nicholson 2003) and reason for concern over the continuing impact of human activities. Oil and gas field development in the habitat of Bullsnakes, with concomitant mortality from increased road traffic, is seen as the principal threat (Didiuk 2003;
Kissner and Nicholson 2003; Alberta Wild Species General Status Listing 2015; COSEWIC 2017). In Alberta, Bullsnake has held "sensitive" status since 2006 (Alberta Wild Species General Status Listing 2015).

In this contribution, we report observations (size and sex distributions, activity over the season, thermal biology, habitat use, and distribution across the landscape) of the Bullsnake population collected incidentally in 1997, during a study of Prairie Rattlesnake (Crotalus viridis) in southeastern Alberta (Powell et al. 1998). We include additional data and analyses as Supplemental Materials: patterns in morphology (sections S1 and S2), capture situation (section S3), environmental temperatures (section S4), and the characteristics of various sites and the number of Bullsnakes caught in those sites (section S5). These additional data go beyond the main goal of this manuscript, but may be useful to others studying Bullsnakes.

\section{Study Area}

The study area was about $30 \mathrm{~km}$ northeast of Medicine Hat, Alberta, in a region of rolling mixed range and cropland, bounded on the west by the South Saskatchewan River (Figure 1); latitude and longitude for the centre of the mapped area: $50.21^{\circ} \mathrm{N}, 110.56^{\circ} \mathrm{W}$. This area has large coulees running to the east and northeast from the river channel, where the South Sas- 


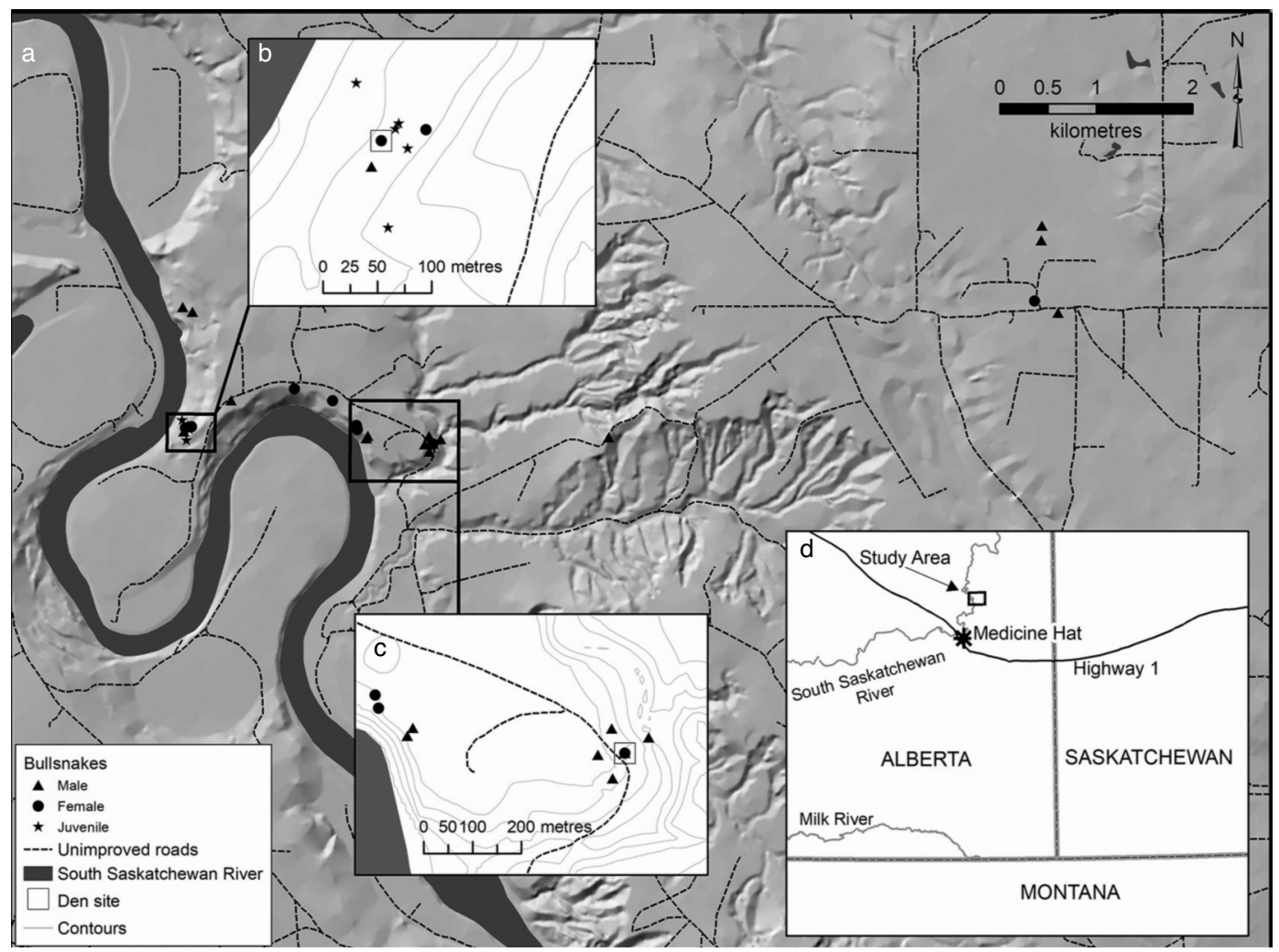

FIGURE 1. a. Relief map of study area and distribution of the 31 Bullsnakes (Pituophis catenifer sayi) captured during this study. Some points represent multiple captures. One capture several kilometres to the south is not included. b-c. Framed areas on main map at higher scale. d. Location of the study area.

katchewan River meanders between large alluvial flats and high steep eroding bluffs with abundant slump blocks. The river bank has a mean elevation of $630 \mathrm{~m}$ above sea level; elevation to the east reaches $770 \mathrm{~m}$.

The rattlesnake radiotelemetry study covered the territory extending $\sim 15 \mathrm{~km}$ to the east of the river, where radio-implanted rattlesnakes were collected and monitored. Tracking the movements of rattlesnakes also took us $\sim 5 \mathrm{~km}$ to the south of the fenced hibernacula, which were the geographic central focuses of the study (Figure 1). Most of this area is rangeland, dotted with gas wells and laced by their access roads and pipelines, with limited areas of cultivation immediately to the east of the fenced hibernacula and at the eastern extremity of monitored rattlesnake movement. Although the study area was not pristine at the time of our study, much of it was unmodified and covered with native vegetation.

Within this general area, Bullsnake captures were restricted to a smaller zone at the west end, bounded to the west by the South Saskatchewan River (Figure 1). The general land cover type within this area is mixed grassland, with small patches of agricultural land predominantly to the northeast (Alberta Biodiversity Monitoring Institute 2010).

\section{Methods}

\section{Hibernaculum study}

Fieldwork was initiated in September 1996. Two hibernacula were identified in the study area. Drift fences and funnel traps were installed in early May 1997 around one of these, which consisted of a series of old Coyote (Canis latrans) dens on the upper slopes of a coulee extending east from the river (Figure 1c). All snakes (including Prairie Rattlesnakes and Wandering Garter Snakes [Thamnophis elegans vagrans]) that emerged after the fences and traps were set up were captured, processed (see below), and released outside the fences. In the spring and fall of 1997, the immediate area of this hibernaculum (henceforth referred to as the fenced dens) was regularly searched for denning activity and snakes of all species, to a distance of $\sim 1 \mathrm{~km}$ north along the east bank of the South Saskatchewan River. All snakes captured in this area (and elsewhere, throughout the study) were processed, and the universal transverse mercator (UTM) locations of the capture points were recorded using a handheld global positioning system receiver: GPS 12 XL (Garmin Ltd., Olathe, Kansas, USA). The traps were reversed in early September 1997, and all captured snakes were released 
inside the fences. The fences and traps were removed on 14 October 1997, terminating the 1997 field season.

\section{Snake capture, measurements, and marking}

Bullsnakes were captured incidentally while we searched for rattlesnake dens, surveyed our fence and traps, searched for free-roaming rattlesnakes, and radiotracked eight rattlesnakes. A large amount of terrain was covered on foot, and activities were carried out daily over the entire study period. We captured, or attempted to capture, all Bullsnakes encountered.

All captured snakes were weighed to the nearest gram with a Light Line spring balance (Model No. 10010 50 g; and Model No. 42500 - 2500 g; PESOLA Präzisionswaagen AG, Schindellegi, Switzerland). Snoutto-vent length (SVL) and tail length were measured by stretching out the snake against a tape measure laid on the ground. Sex was determined by cloacal probing, although not always with certainty for very young snakes (which were categorized as juveniles and not included in sex-ratio calculations). All snakes of sufficient size ( $\geq 40 \mathrm{~cm}$ SVL) were individually marked with Passive Integrated Transponder (PIT) tags (Anitech TX 1412L, Anitech Enterprises, Inc., Markham, Ontario, Canada), injected dorsally on the left side of the vertebral column $\sim 4 \mathrm{~cm}$ ahead of the tail base. Smaller snakes were marked using individual subcaudal scute clip patterns. Recaptures at intervals of more than three weeks were remeasured, as described above. Recaptures of shorter duration were subjected only to PIT tag reading and the collecting of associated environmental data.

At the time of all hand captures, we recorded the temperature (shaded) of the ground, as near as possible to the spot where the snake was resting, UTM coordinates, brief descriptions of weather conditions (including the temperature of the air at $1 \mathrm{~m}$ ), and the capture situation (activities, if any, and posture) of the snake.

To determine whether adult and juvenile Bullsnakes select different environmental temperatures, we compared mean ground temperatures and mean air temperatures at $1 \mathrm{~m}$ for male, female, and juvenile hand captures by means of analysis of variance (ANOVA). To test for possible relations between insolation and surface activity, we cross-tabulated our insolation categories (overcast, sunny, or mixed sun and cloud) and snake capture situation and performed a $\chi^{2}$ test for random association on the resultant table. All statistical tests were carried out using PAST (Hammer et al. 2001). Results of these analyses are provided in Supplemental Material sections S3 and S5.

\section{Mapping}

Our GPS data for each hand capture allowed us to examine the distribution of Bullsnakes across the landscape relative to biotic and abiotic characteristics. We used ArcGIS software (version 10.5; Esri, Redlands, California, USA) for visualization and spatial analysis. A shapefile layer of the Bullsnake captures was created from the recorded GPS coordinates, which were in a UTM zone $12 \mathrm{~N}$ projection. This layer was overlain on various thematic layers (in shapefile, geodatabase, and Esri grid formats) to determine the following characteristics of the Bullsnake capture locations: topography, generalized land cover, vegetation, and human impact.

Topography was represented by hill shading generated from a digital 10-m resolution elevation model (AltaLIS 2010). Generalized land cover classifications were determined using the Alberta Biodiversity Monitoring Institute's (ABMI 2010) Land Cover Inventory dataset. Site types (landforms/landscape categorization) were determined from the grassland vegetation inventory (Alberta Sustainable Resource Development 2010a,b) and native vegetation from the native prairie vegetation inventory (Alberta Sustainable Resource Development 2004). Human impact factors came from the following sources: agricultural uses from ABMI's (2014) Wall-to-Wall Human Footprint Inventory; roads from the 2016 AltaLIS roads layer; and pipelines and wells from the Alberta Energy Regulator (2017a,b). We superimposed our 1997 Bullsnake distribution data onto two maps (1997 and 2017) depicting gas wells and gas line emplacements, to examine the relationship of Bullsnake habitat use to such features and demonstrate changes in human use of the landscape over this period.

\section{Results}

\section{Capture numbers and seasonal distribution}

Over the study period, we captured 31 Bullsnakes. Three were recaptured once, and the capture-recapture interval for two was sufficient to require re-measurement. One Bullsnake was recovered from a trap at the fenced dens in the spring (13 May) and six in the fall (6 September to 10 October). Four Bullsnakes were hand captured in the vicinity of dens in the spring and early summer and 10 in the fall (1 September to 3 October). The remaining 10 were encountered while searching for rattlesnakes across the study area. Our adult Bullsnake sample consisted of 16 males and nine females (Table S1), and thus exhibited a proportion of males (males/[males + females]) of 0.64 .

Our first capture occurred on 11 May (several Bullsnakes were encountered in the area of the river before this, but were not captured) and our last on 10 October (Figures S1, S2). A gap is evident between 12 June and 19 August (days 163-231) in which only one capture was made, although one dead adult Bullsnake was found on a gas field access road on 2 August.

\section{Hibernacula}

Two hibernacula were identified in the study area. The first, the fenced dens, is described above (Figure 1b). The second was located high in an area of slumped terrain immediately above the South Saskatchewan River, facing northeast (Figure 1c). Although other concentrations of Bullsnake captures in similar situations along the course of the river may represent additional overwintering sites, we cannot confidently state that 
snakes congregating at them were associating with hibernacula.

Taking the presence of snakes in funnel traps to indicate timing of hibernacula use, egress ended on 13 May and ingress began on 6 September, continuing until 10 October.

\section{Lengths and masses of the snakes}

We divided all captured snakes into males, females, and juveniles, i.e., young-of-the-year, sex undetermined (Table S1). The distributions of male and female SVLs overlapped broadly and were discontinuous for both sexes (Figure S3). Males fell into two SVL classes: a small number ranging between 59 and $74 \mathrm{~cm}$ and the remainder between 104 and $134 \mathrm{~cm}$. A small number of females were distributed over the $40-60 \mathrm{~cm}$ and the $80-90 \mathrm{~cm}$ intervals, but most lay within the $110-130 \mathrm{~cm}$ interval. Hatchlings were mostly within the $30-40 \mathrm{~cm}$ interval of the SVL distribution, although one exceeded $50 \mathrm{~cm}$. The SVL distributions of both males and females overlapped that of hatchlings at their lower ends.

The distributions of male and female masses likewise overlapped broadly (Figure S4). Male masses fell into three groups: $50-150 \mathrm{~g}, 250-450 \mathrm{~g}$, and $500-750 \mathrm{~g}$. The groups into which female masses fell were more tightly defined: $48-200 \mathrm{~g}, 400-450 \mathrm{~g}$, and 600-650 g. Juveniles comprised a single mass class, $<50 \mathrm{~g}$, which overlapped the lower end of the female mass distribution.

These SVL and mass distributions suggest that Bullsnakes at this location fall into clearly defined size categories. Given the small sample size, further division of snake size distributions is unwarranted.

Growth data are available for only two individuals that were captured twice (Table S2), both adult males that fell into the adult male SVL division at first capture. The smaller snake's increase in mass moved it from the subadult mass class to the adult mass class over the capture-recapture period.

\section{Movement}

Movement data are available for the two males that were recaptured. The larger of these was captured on 9 June, and recaptured on 2 July (Table S2), moving $96 \mathrm{~m}$ nearly due north over this 22 -day period. Both capture and recapture were on flat uplands, among the furthest of our captures from the river. The smaller one was captured on 13 May and recaptured on 20 September, moving $375.5 \mathrm{~m}$ in a southwest direction over this 130 day interval, from grassland immediately adjacent to a promontory delimited by the river to a slump on the northwest-facing side of this promontory

\section{Capture situation and insolation}

The greatest numbers of hand captures, in the widest range of situations, were made on sunny days or days with mixed sun and cloud. These data are tabulated and the results of a $\chi^{2}$ analysis for association are given in Table S3.

\section{Environmental temperatures}

The distributions of the air and ground temperatures experienced by males, females, and juveniles overlapped broadly (Figure S5).

\section{Distribution over landscape}

The great majority of Bullsnakes were captured in the immediate vicinity of the South Saskatchewan River, on the bluffs overlooking the channel (Figure 1). One of the two dens identified was near the top of a steep slope forming the upper reaches of the river channel; the other (the fenced dens) lay on the upper reaches of a seasonal channel in close proximity to the river. Only six Bullsnakes were captured at any distance from the South Saskatchewan River, two of which were associated with coulees formed by temporary watercourses draining into the South Saskatchewan. Four were located on relatively flat uplands $\sim 7 \mathrm{~km}$ from the South Saskatchewan; the distance was calculated from the easternmost meander of the river, as we could not be certain of the den in which these snakes overwintered. Juveniles were restricted to the immediate vicinity of the river. Bullsnakes captured at the greatest distance from the river (three males, one female) were all in the adult SVL class.

The area immediately adjacent to the South Saskatchewan River, where most captures were made and both dens were located (Figure 1), is divided between "thin breaks", "limy", and "overflow" site types (Alberta Sustainable Resource Development 2010a,b), covering the steeper slopes of the river channel. Adjacent inland terrain is classified as sand-likely Aeolian or glaciofluvial in this area (Alberta Sustainable Resource Development 2010a,b). Descriptions of these pertinent site types (Alberta Sustainable Resource Development 2010a,b) and numbers of Bullsnake captures made in each are provided in Table S4. Bullsnakes captured at upland locations were found on margins of tame pasture (two captures), and crop site types (two captures).

Shrub coverage over the study area ranged between the $0-2 \%$ and $31-60 \%$ class intervals (Alberta Sustainable Resource Development 2004). All Bullsnake captures were made in areas of $0-10 \%$ shrub coverage, the majority being within the $3-6 \%$ category.

\section{Nesting}

We found one Bullsnake nest (1 September) in our study area, located low on the slope of an area of choppy sandhills site type (duned surface of loamy sand and sand soils, with thin vegetation cover; Alberta Sustainable Resource Development 2010a,b), 2.2 km north by northeast of the northernmost Bullsnake hand capture. The nest had evidently been excavated by a predator of undetermined identity. Some of the eggs had been consumed, leaving only the shells, but, as a single hatchling shed skin was found next to the nest, others had evidently hatched. 
Interactions with human landscape modifications

Bullsnakes were generally not associated with human-built structures. Although an unimproved road and a gas pipeline ran along the top of slopes defining the river channel in the area with the greatest density of captures (Figures 1, 2a), snake captures here were almost entirely confined to the slopes themselves. The four captures made away from the river were associated with unimproved roads or areas of modified prairie and were the only ones made in the vicinity of agricultural artifacts. Our two mapped hibernacula were closely associated with buried gas lines, but no Bullsnakes were captured in the vicinity of gas wells (Figure 2a). One Bullsnake was found run over, evidently by a gas field maintenance vehicle, on a gas field access road (not mapped), on 2 August. Two of our hand captures were made on unimproved roads (Table S3).

A marked increase in the density of gas wells and gas lines in the study area has occurred between 1997 and 2017 (Figure 2). The majority of Bullsnake captures in 1997 occurred in areas still untouched in 2017 by gas field development, but much of the terrain east of the South Saskatchewan River has been dissected by such development in the intervening 20 years.

\section{Discussion}

The bias in favour of male snakes in our capture sample is similar to that reported elsewhere. For example, the proportion of male adult and juvenile Bullsnakes captured in drift fences during one active season in the adjacent Canadian Forces Base (CFB) Suffield and Suffield National Wildlife Area (Table S2 in Didiuk 2003) was 0.57, which does not differ significantly from our data $\left(\chi_{1}^{2}=0.97, P=0.32\right)$. A male bias in Bullsnake captures, and at hatching, has been noted in Nebraska (Gutzke et al. 1985; but see Kapfer et al. 2008a, for Wisconsin), indicating that the skewed sex ratio in our sample was not a result of intersexual differences in mortality or catchability (Gutzke et al. 1985). Also, the lack of significant sexual size dimorphism in our sample (Table S1) has been noted in other parts of the range of this species (Diller and Wallace 1996; Kapfer 2009), although the largest individuals in many populations are males (Kapfer 2009).

The mass and SVL of our juvenile, subadult, and adult Bullsnakes correspond roughly to those of Didiuk (2003). Iverson et al. (2008) distinguished a firstyear class in their Nebraska Bullsnake sample, but, in that study, body size distribution did not otherwise fall into obvious age or size classes. Bullsnakes in a Wisconsin population were divided among four age-size categories (Kapfer et al. 2008a).

The number of Bullsnakes (31) captured over the five months of our study was small compared with the number of Prairie Rattlesnakes (333) captured in the same area over the same period. We recaptured only three Bullsnakes over this period, although 129 of our marked Prairie Rattlesnakes were recaptured at least once (Powell et al. 1998), suggesting that the Bullsnake population is much smaller than the syntopic rattlesnake one. This discrepancy is not reflective of a lack of active sampling effort; suitable habitat for both species was searched frequently over most of the study period, even though rattlesnakes were the desired target of these efforts. The number of Bullsnakes captured in the fenced dens in the fall (11) was also much smaller than the number of rattlesnakes taken at these dens (62). Bullsnakes were observed climbing the fences surrounding these dens, whereas rattlesnakes were not; thus, this capture method may have been unreliable for the former species, although the traps and fence were set up for the greater portion of the period in which snakes were returning to the dens. However, if we assume that the relative numbers of Bullsnakes and Prairie Rattlesnakes captured by passive methods in the fall roughly represent relative population sizes, Bullsnakes are still present in much smaller numbers.

A study of snake movements and numbers in the nearby CFB Suffield and Suffield National Wildlife Area used drift fence arrays set at successively greater distances from the South Saskatchewan River and close to hibernacula in the vicinity of the river (Didiuk 2003). The numbers of Bullsnakes and Prairie Rattlesnakes captured in drift fences over a time span comparable to our study period (395 rattlesnakes, 307 Bullsnakes; Didiuk 2003) did not show the same relative abundance as shown by our data. The habitat in Didiuk's (2003) study area was similar to that in ours. Human presence in the Suffield National Wildlife Area and CFB Suffield is greatly restricted, but gas field activities are conducted in the National Wildlife Area and grazing has been permitted in adjacent areas of the military reserve. Thus, it is unlikely that environmental differences are responsible for the differences in relative numbers of Bullsnakes and Prairie Rattlesnakes between Didiuk's (2003) study and ours.

If Bullsnakes spend the majority of the active season underground (Brown and Parker 1982; Ernst and Ernst 2003; Rodríguez-Robles 2003), walking surveys are likely to miss their presence, whereas the drift fence arrays used by Didiuk (2003) would catch snakes active on the surface, if they were moving significant distances. Our primary method for capturing Bullsnakes away from the vicinities of hibernacula may, thus, have been unsuitable for accruing a representative sample in our study area.

Bullsnake densities appear to be low elsewhere in its range (Fitch 1982; Kapfer et al. 2008a). Our findings are consistent with this. Smaller numbers and lower densities in Alberta Bullsnake populations, which are the northernmost of the species' geographical distribution (Russell and Bauer 2000; Ernst and Ernst 2003; Kissner and Nicholson 2003), are to be expected relative to populations further south. Bullsnakes are oviparous (Russell and Bauer 2000; Ernst and Ernst 2003; Kissner and Nicholson 2003; Wright 2008), and the 
a
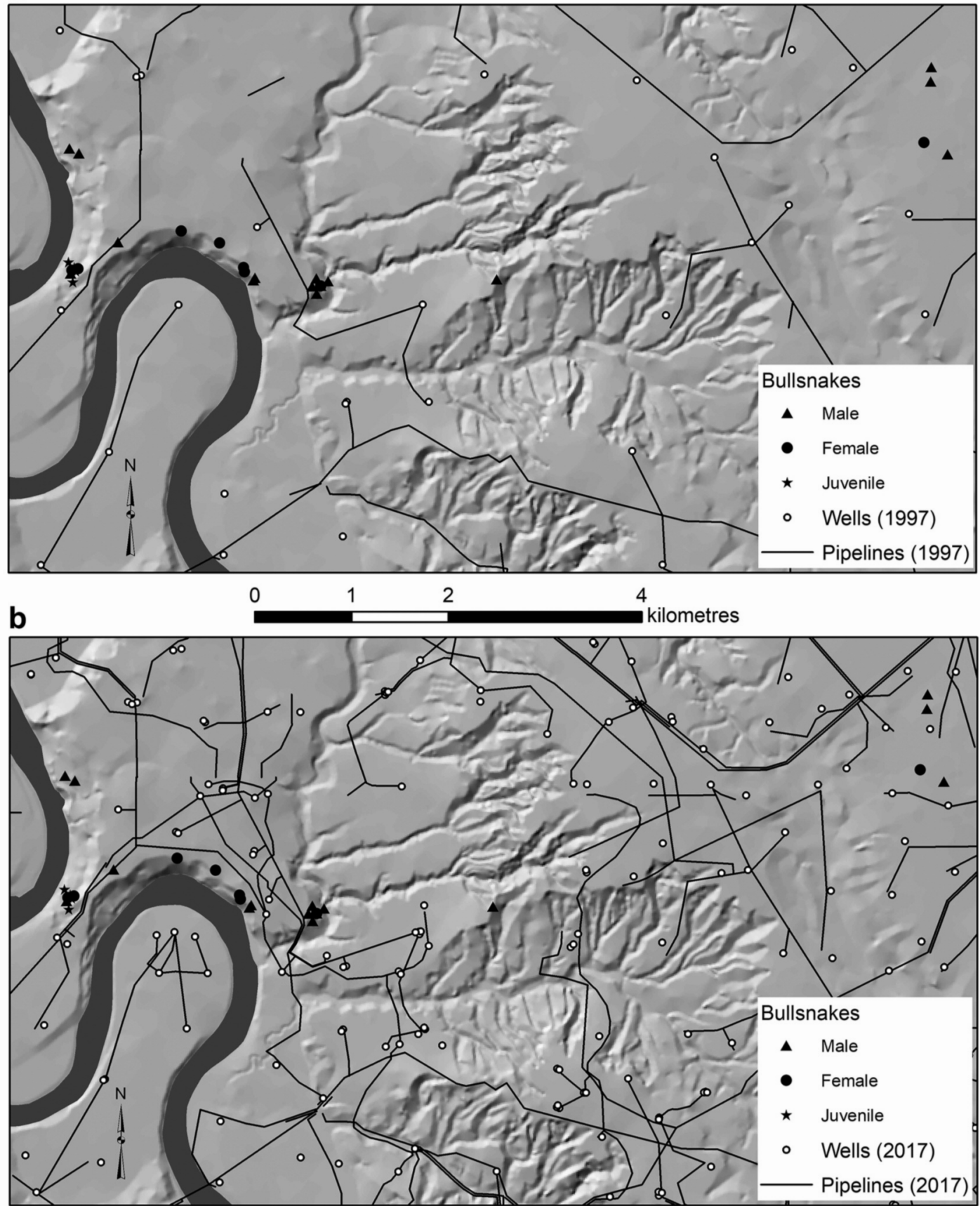

Figure 2. a. Study area displaying Bullsnake (Pituophis catenifer sayi) captures in relation to gas wells (open circles) and gas pipelines (black lines) in place in 1997. b. Bullsnake captures of 1997 superimposed on map of gas wells and gas pipelines in place in 2017. 
success or failure of incubation will depend on seasonal weather conditions and, thus, will potentially vary greatly from year to year at this latitude (Wright 2008). Wright (2008) found that Bullsnake nests in the vicinity of Drumheller, Alberta, were restricted to the microclimatic conditions found in coulees and canyons, a factor that imposes limitations on recruitment.

The seasonal pattern of activity exhibited by Bullsnakes in our study (Figures S1 and S2) is consistent with that reported elsewhere (Brown and Parker 1982; Didiuk 2003; Kapfer et al. 2008b; Gardiner et al. 2013). Our fieldwork did not begin until early May, and our encounters with several individuals before the commencement of data collection indicated that we missed that portion of the Bullsnake population that emerged prior to this (Didiuk 2003; Kissner and Nicholson 2003; Gardiner et al. 2013). However, the fencing and open traps around the fenced dens were maintained sufficiently late in the fall that we are confident that our data are indicative of activity during this period. No Bullsnakes emerged after mid-May, and return to the fenced dens began on 6 September. Didiuk (2003), at his South Saskatchewan River hibernacula, recorded protracted emergence in spring and dispersal from hibernaculum areas by May, and Bullsnakes began appearing in the vicinities of hibernacula in September (Didiuk 2003). For a Utah population of Great Basin Gophersnake (Pituophis catenifer deserticola) the timing of spring emergence was more tightly constrained by environmental temperature than that of fall return (Vetas 1951). We have no information on seasonal environmental temperature cues for Alberta Bullsnake populations, but a similar relationship appears likely, as fall returns to the fenced dens took place over a 6-week period, while spring emergence was apparently largely complete early in the active season.

We have posited that the prolonged lacuna in Bullsnake captures in mid- to late-summer (Figures S1 and S2) may be due to a strong tendency toward fossorial activity. Bullsnakes have been noted to spend the greater proportion of the active season in burrows (Brown and Parker 1982; Rodríguez-Robles 2002, 2003; Ernst and Ernst 2003). Over their range, they feed preferentially on rodents and other small mammals (Hisaw and Gloyd 1926; Brown and Parker 1982; Fitch 1982; Reynolds and Scott 1982; Cook 1984; Diller and Johnson 1988; Diller and Wallace 1996; Rodríguez-Robles 1998, 2002; Russell and Bauer 2000; Ernst and Ernst 2003; Kissner and Nicholson 2003; COSEWIC 2017). They are accomplished diggers (Carpenter 1982; Sterner et al. 2002); Fitch (1982) considered Bullsnakes to be specialized for hunting pocket gophers (Thomomys spp.) in their tunnels. It is thus possible that many of the Bullsnakes in our study area that had dispersed away from the vicinity of the South Saskatchewan River from 12 June to 19 August were actively hunting or lying quiescent underground and were only active on the surface for short periods. Capture situations (Table S3), whether adjacent to the river or elsewhere, would thus repre- sent surface activity of individuals that had emerged temporarily from their fossorial pursuits. Martino et al. (2012) found that the presence of burrows was the best predictor of Bullsnake activity in Grasslands National Park; a minority of our hand captures were made adjacent to burrows or holes (Table S3), but we surveyed only the area in the immediate vicinity of the capture. Thus, this relationship may hold true for our hand captures as well. If summer fossoriality is the rule for Bullsnakes, the difference in relative numbers between them and Prairie Rattlesnakes may be more apparent than real. Our data do not allow us to test this hypothesis.

Most of our Bullsnake hand captures were made in the vicinity of the river (Figure 1), early and late in the active season (Figures S1 and S2). If our assumption is correct that activity further from the river takes place largely underground, Bullsnakes must have moved away from the area adjacent to the river after their period of activity there early in the summer, and moved back late in the summer. Didiuk (2003) recorded most adult Bullsnake captures within $0.2-1 \mathrm{~km}$ of the South Saskatchewan River valley rim, but small numbers of captures were made as far as $13.5 \mathrm{~km}$ from the river. Bullsnakes exhibited strong directionality in spring dispersal away from the river and fall return to it (Didiuk 2003), and individual movements between capture and recapture points could be quite rapid (Didiuk 2003). However, Didiuk (2003) reported Bullsnake captures within $1 \mathrm{~km}$ of the river over the entire summer, in contrast to our data (Figures S1 and S2). Gardiner et al. (2013) reported that home ranges of Bullsnakes in Grasslands National Park, Saskatchewan, exhibited a dumbbell shape - two activity areas (around the hibernaculum and the area of summer activity) separated by a transit corridor, which was traversed quickly in the spring and fall. Our few captures in upland habitat, some $7 \mathrm{~km}$ from the easternmost point along the course of the river, are likely of adult snakes that moved this distance (or some fraction thereof). These snakes could represent a portion of the population that moved comparable distances from the river to those of some of Didiuk's (2003) widely-ranging adult Bullsnakes, but it does not appear to be a large portion. However, again, the propensity of Bullsnakes to spend a great deal of time underground could result in underestimation.

Elsewhere in its distribution, Gophersnake has been shown to overwinter individually, instead of in communal dens shared with other species (Williams et al. 2012). This has not been recorded in Alberta, but if some of the Bullsnakes from our study did overwinter individually in dens located away from the South Saskatchewan River, they would not be required to make long seasonal dispersals to upland habitat. Further data on Bullsnake movement in Alberta is required to test this possibility.

Martino et al. (2012), examining Bullsnake movement in Grasslands National Park, Saskatchewan, found that they travelled 493-3946 m (mean $1709 \pm 256 \mathrm{~m})$ 
during the active season, with a mean daily movement of $52 \pm 7 \mathrm{~m}$. The distances moved by Bullsnakes in Grasslands National Park were much smaller than those recorded for Bullsnakes denning along the South Saskatchewan River (Didiuk 2003; Martino et al. 2012). Evidently Bullsnakes exhibit annual movement patterns that accord with local topography, the locations of hibernacula within it, and, presumably, resource availability across it. Studies of Gophersnake home range area and movement elsewhere in the species' geographical distribution (Fitch and Shirer 1971; Rodríguez-Robles 2003; Kapfer et al. 2008b) indicate much shorter movements and smaller home ranges than those described for Bullsnakes in Alberta (Didiuk 2003) and Saskatchewan (Martino et al. 2012; Gardiner et al. 2013).

Bullsnake hand captures were generally made close to unimproved roads (Figure 1) and to gas field lines, but never around gas well installations (Figure 2a). Few captures were made in the vicinity of agricultural modifications: installations, equipment, or modified land. Road mortality, particularly resulting from oil and gas field activity, is seen as one of the more pressing threats to Bullsnake populations in Alberta (Didiuk 2003; Kissner and Nicholson 2003; COSEWIC 2017). In the area of Grasslands National Park, Saskatchewan, Bullsnakes were found in the vicinity of roads at four times the expected rate for the area occupied by roads (Martino et al. 2012). Fortney et al. (2012) also found that Bullsnakes in Grassland National Park tended to be found on, and close to, roads, this tendency being a function of the proximity of roads to hibernacula and of the type of road (paved, gravel, trail). The area over which our Bullsnake population occurred did not feature any paved roads, and the roads present at that time experienced low levels of traffic. Even so, we recorded one road fatality during our study period, which suggests that road mortality is a constant possibility even here.

Our data were collected in 1997. At that time, gas field installations were relatively few and widely scattered across the area of Bullsnake activity (Figure 2a). In the intervening 21 years, a marked increase in the number of wells and gas lines is evident, both in the vicinity of the hibernacula and across the presumed summer foraging range of the snakes (Figure $2 b$ ). This will inevitably have been accompanied by an increase in vehicular traffic and its associated likelihood of Bullsnake road mortality.

The data presented here provide a baseline for numbers and activity of this species across a landscape for which human activity is well-documented, both at present and over two decades ago. This may be useful for future studies of the impact of increased human activity on a Bullsnake population at the northern extremities of its geographic distribution.

\section{Acknowledgements}

Funding for the 1997 fieldwork came from the Alberta Conservation Association, the Alberta Sports, Recreation, Parks and Wildlife Foundation, and the Friends of the Environment Foundation of Medicine Hat. We are very grateful to the staff of the Medicine Hat office of Alberta Environmental Protection, Natural Resources Service, particularly Dale Eslinger and Sharon Otto, for logistic support in the field. We thank Ed Ruff, of Medicine Hat, for help in picking a study site and in getting our trap arrays set up in the spring. We thank Bill Davies, of the Davies Cattle Company, and his family for allowing us to work on their land. We are obliged to Jonathan Wright for his timely assistance in the field, advice, and continuing interest in the project. Our very capable and assiduous field crew, Joanne Skilnick, Margaret Hill, and Nancy O'Brien, are gratefully acknowledged for their labours in the field. All research and collection was undertaken under Alberta Environmental Protection licence 1668 and Alberta Environmental Protection research permit 0405 GP, both issued to A.P.R. The comments of two anonymous reviewers greatly improved this paper.

We are pleased to be able to contribute to this tribute to Francis Cook, who has played such a fundamental role in furthering our understanding of the amphibians and reptiles of Canada and in inspiring others to explore the biology of these underappreciated components of this nation's vertebrate fauna. In his iconic book, Introduction to Canadian Amphibians and Reptiles (1984, page 175), he states: "Any interested naturalist has an opportunity to make a useful contribution to our knowledge through detailed observations of local habitats... for all species". Our contribution is made in this spirit.

\section{Literature Cited}

ABMI (Alberta Biodiversity Monitoring Institute). 2010. Wall-to-wall land cover inventory [geodatabase]. ABMI, Edmonton, Alberta, Canada. Accessed 6 December 2017. http://www.abmi.ca/home/data-analytics/da-top/da-productoverview/GIS-Land-Surface/Land-Cover.html.

ABMI (Alberta Biodiversity Monitoring Institute). 2014. Wall-to-wall human footprint inventory [geodatabase]. ABMI, Edmonton, Alberta, Canada. Accessed 6 December 2017. http://www.abmi.ca/home/data-analytics/da-top/daproduct-overview/GIS-Land-Surface/HF-inventory.html.

Alberta Energy Regulator. 2017a. Pipelines [shapefile]. Alberta Energy Regulator, Calgary, Alberta, Canada. Accessed 27 November 2017. https://www.aer.ca/providing-informa tion/data-and-reports/maps-mapviewers-and-shapefiles.

Alberta Energy Regulator. 2017b. List of wells in Alberta [shapefile]. Alberta Energy Regulator, Calgary, Alberta, Canada. Accessed 27 November 2017. https://www.aer.ca/ providing-information/data-and-reports/statistical-reports /st37.

Alberta Sustainable Resource Development. 2004. Native prairie vegetation inventory [shapefile]. Spatial \& Numeric Data Services, University of Calgary (distributor), Calgary, Alberta, Canada.

Alberta Sustainable Resource Development. 2010a. Grassland vegetation inventory [shapefile]. Spatial \& Numeric 
Data Services, University of Calgary (distributor), Calgary, Alberta, Canada.

Alberta Sustainable Resource Development. 2010b. Grassland vegetation inventory (GVI) specifications. 5th edition. Government of Alberta, Edmonton, Alberta, Canada.

Alberta Wild Species General Status Listing. 2015. Wild species status search. Accessed 3 February 2018. http://aep. alberta.ca/fish-wildlife/species-at-risk/wild-species-status -search.aspx.

AltaLIS. 2010. Alberta province-wide digital elevation model grid format [raster]. Spatial \& Numeric Data Services, University of Calgary (distributor), Calgary, Alberta, Canada.

Brown, W.S., and W.S. Parker. 1982. Niche dimensions and resource partitioning in a Great Basin Desert snake community. Pages 59-81 in Herpetological Communities: A Symposium of the Society of the Study of Amphibians and Reptiles and the Herpetologists' League, August 1977. Edited by N.J. Scott, Jr. Wildlife research report 13. United States Fish and Wildlife Service, Washington, DC, USA.

Carpenter, C.C. 1982. The Bullsnake as an excavator. Journal of Herpetology 16: 394 401. https://doi.org/10.2307/ 1563570

Cook, F.R. 1984. Introduction to Canadian Amphibians and Reptiles. National Museums of Canada, Ottawa, Ontario, Canada.

COSEWIC (Committee on the Status of Endangered Wildlife in Canada). 2017. COSEWIC assessment and status report on the Bullsnake Pituophis catenifer sayi in Canada. COSEWIC. Ottawa, Ontario, Canada. Accessed 27 January 2018. http://www.registrelep-sararegistry.gc.ca/ virtual_sara/files/cosewic/sr_Bullsnake_2017_e.pdf.

Didiuk, A.B. 2003. CFB Suffield and Suffield National Wildlife Area. Cooperative reptile and amphibian studies. Snake conservation research and management 2002. Canadian Wildlife Service, Prairie and Northern Region, Edmonton, Alberta, Canada. Accessed 17 November 2017. http://www. ceaa-acee.gc.ca/050/documents/29548/29548E.pdf.

Diller, L.V., and D.R. Johnson. 1988. Food habits, consumption rates, and predation rates of western rattlesnakes and gopher snakes in southwestern Idaho. Herpetologica 52: 228-233.

Diller, L.V., and R.L. Wallace. 1996. Comparative ecology of two snake species (Crotalus viridis and Pituophis melanoleucus) in southwestern Idaho. Herpetologica 52: 343360.

Ernst, C.H., and E.M. Ernst. 2003. Snakes of the United States and Canada. Smithsonian Books, Washington, DC, USA.

Fitch, H.S. 1982. Resources of a snake community in prairiewoodland habitat of northeastern Kansas. Pages 83-97 in Herpetological Communities: A Symposium of the Society for the Study of Amphibians and Reptiles and the Herpetologists' League, August 1977. Edited by N.J. Scott, Jr. Wildlife research report 13. United States Fish and Wildlife Service, Washington, DC, USA.

Fitch, H.S., and H.W. Shirer. 1971. A radio telemetric study of spatial relationships in some common snakes. Copeia 1971: 118-128. https://doi.org/10.2307/1441605

Fortney, A.N., R.G. Poulin, J.A. Martino, D.L. Parker, and C.M. Somers. 2012. Proximity to hibernacula and road type influence potential road mortality of snakes in southwestern Saskatchewan. Canadian Field-Naturalist 126: 194-203. https://doi.org/10.22621/cfn.v126i3.1360

Gardiner, L.E., C.M. Somers, J.A. Martino, D.L. Parker, and R.G. Poulin. 2013. Balancing the dumbbell: summer habitats need protection in addition to winter dens for northern snake communities. Journal of Wildlife Management 77: 975-982. https://doi.org/10.1002/jwmg.555

Gutzke, W.H.N., G.L. Paukstis, and L.L. McDaniel. 1985. Skewed sex ratios for adult and hatchling Bullsnakes, Pituophis melanoleucus, in Nebraska. Copeia 1985: 649652. https://doi.org/10.2307/1444757

Hammer, Ø., D.A.T. Harper, and P.D. Ryan. 2001. PAST: Paleontological statistics software package for education and data analysis. Palaeontologia Electronica 4: 1-9.

Hisaw, F.L., and H.K. Gloyd. 1926. The bull snake as a natural enemy of injurious rodents. Journal of Mammalogy 7: 200-205. https://doi.org/10.2307/1373511

Iverson, J.B., C.A. Young, and T.S. Akre. 2008. Body size and growth in the Bullsnake (Pituophis catenifer sayi) in the Nebraska Sandhills. Journal of Herpetology 42: 501507. https://doi.org/10.1670/07-030.1

Kapfer, J.M. 2009. Body size and sexual size dimorphism of Bullsnakes (Pituophis catenifer sayi) in Wisconsin, USA. Herpetological Conservation and Biology 4: 353-357.

Kapfer, J.M., J.R. Coggins, and R. Hay. 2008a. Estimates of population size, measurements of sex ratios, and reported mortality rates for Bullsnakes (Pituophis catenifer sayi) at a site in the upper midwestern United States. Journal of Herpetology 42: 265-269. https://doi.org/10.1670/07-2021.1

Kapfer, J.M., J.R. Coggins, and R. Hay. 2008b. Spatial ecology and habitat selection of Bullsnakes (Pituophis catenifer sayi) at the northern periphery of their geographic range. Copeia 2008: 815-826. https://doi.org/10.1643/CE-07-104

Kissner, K.J., and J. Nicholson. 2003. Bullsnakes (Pituophis catenifer sayi) in Alberta: literature review and data compilation. Species at risk report 62. Alberta Sustainable Resource Development, Fish and Wildlife Division, Edmonton, Alberta, Canada.

Martino, J.A., R.G. Poulin, D.L. Parker, and C.M. Somers. 2012. Habitat selection by grassland snakes at northern range limits: implications for conservation. Journal of Wildlife Management 76: 759-767. https://doi.org/10.1002/ jwmg. 313

Powell, G.L., A.P. Russell, M.M.A. Hill, N.E. O'Brien, and J.L. Skilnick. 1998. A preliminary investigation of movements, habitat use, and population trends in the prairie rattlesnake (Crotalus viridis) in a multiple-use rural landscape in southeastern Alberta. The 1997 field season. Alberta Conservation Association, Edmonton, Alberta, Canada.

Reynolds, R.P., and N.J. Scott, Jr. 1982. Use of a mammalian resource by a Chihuahuan snake community. Pages 99-118 in Herpetological Communities: A Symposium of the Society for the Study of Amphibians and Reptiles and the Herpetologists' League, August 1977. Edited by N.J. Scott, Jr. Wildlife research report 13. United States Fish and Wildlife Service, Washington, DC, USA.

Rodríguez-Robles, J.A. 1998. Alternative perspectives on the diet of Gopher Snakes (Pituophis catenifer, Colubridae): literature records versus stomach contents of wild and museum specimens. Copeia 1998: 463-466. https://doi.org/ $10.2307 / 1447442$

Rodríguez-Robles, J.A. 2002. Feeding ecology of North American gopher snakes (Pituophis catenifer, Colubridae). Biological Journal of the Linnean Society 77: 165-183. https://doi.org/10.1046/j.1095-8312.2002.00098.x

Rodríguez-Robles, J.A. 2003. Home ranges of Gopher Snakes (Pituophis catenifer, Colubridae) in Central California. Copeia 2003: 391-396. https://doi.org/10.1643/00458511(2003)003[0391:HROGSP]2.0.CO;2 
Russell, A.P., and A.M. Bauer. 2000. The Reptiles and Amphibians of Alberta. 2nd Edition. University of Calgary Press, Calgary, Alberta, Canada.

Somers, C.M., C.F. Graham, J.A. Martino, T.R. Frasier, S.L. Lance, L.E. Gardiner, and R.G. Poulin. 2017. Conservation genetics of the eastern yellow-bellied racer (Coluber constrictor flaviventris) and bullsnake (Pituophis catenifer sayi): river valleys are critical features for snakes at northern range limits. PLoS ONE 12: e0187322. https: //doi.org/10.1371/journal.pone.0187322

Sterner, R.T., B.E. Petersen, S.A. Shumake, S.E. Gaddis, J.B. Bourassa, T.A. Felix, G.R. McCann, K.A. Crane, and A.D. Ames. 2002. Movements of a Bullsnake (Pituophis catenifer) following predation of a radio-collared northern pocket gopher (Thomomys talpoides). Western North American Naturalist 62: 240-242.
Vetas, B. 1951. Symposium: a snake den in Tooele County, Utah: temperatures of entrance and emergence. Herpetologica $7: 15-20$.

Williams, K.E., K.E. Hodges, and C.A. Bishop. 2012. Small reserves around hibernation sites may not adequately protect mobile snakes: the example of Great Basin Gophersnakes (Pituophis catenifer deserticola) in British Columbia. Canadian Journal of Zoology 90: 304-312. https://doi. org/10.1139/z11-136

Wright, J.D. 2008. Bullsnake, Pituophis catenifer sayi, nesting biology in Alberta. Canadian Field-Naturalist 122: 138141. https://doi.org/10.22621/cfn.v122i2.572

Received 6 February 2018

Accepted 18 June 2018

\section{SUPPLEMENTARY MATERIAL:}

SECTION S1. Size of Bullsnakes (Pituophis catenifer sayi).

SECTION S2. Snout-to-vent length and mass of recaptured Bullsnakes (Pituophis catenifer sayi).

SECTION S3. Capture situation and insolation during capture of Bullsnakes (Pituophis catenifer sayi).

SECTION S4. Environmental temperature measured during hand capture of Bullsnakes (Pituophis catenifer sayi).

SECTION S5. Site types of hand captures of Bullsnakes (Pituophis catenifer sayi).

TABLE S1. Summary of the lengths and masses of all captured Bullsnakes (Pituophis catenifer sayi).

TABLE S2. Growth and movement data for the two Bullsnakes (Pituophis catenifer sayi) recaptured after an interval $>3$ weeks.

TABLE S3. Cross-tabulation of situation at capture with insolation for all hand-captured Bullsnakes (Pituophis catenifer sayi).

TABLE S4. Numbers of Bullsnakes (Pituophis catenifer sayi) hand captured in each site type in the 1997 field season.

Figure S1. Distribution of snout-to-vent lengths (SVL) of Bullsnakes (Pituophis catenifer sayi) captured over the study period, 11 May (day 131) to 10 October (day 283) 1997.

Figure S2. Mass of Bullsnakes (Pituophis catenifer sayi) captured over the study period, 11 May (day 131) to 10 October (day 283) 1997.

FigURE S3. Distribution of snout-to-vent lengths (SVL) of all Bullsnakes (Pituophis catenifer sayi) captured over the study period, 11 May to 10 October 1997.

Figure S4. Distribution of mass of all Bullsnakes (Pituophis catenifer sayi) captured over the study period, 11 May to 10 October 1997.

FIGURE S5. Ground (a) and air (b) temperatures for all hand captures of Bullsnakes (Pituophis catenifer sayi). 